University of South Florida

DIGITAL COMMONS

Digital Commons @ University of

@ UNIVERSITY OF SOUTH FLORIDA

South Florida

Marine Science Faculty Publications

College of Marine Science

$11-5-2009$

\title{
Low-Frequency Exchange of Mass Between Ocean Basins
}

Don P. Chambers

University of South Florida, donc@usf.edu

Josh K. Willis

California Institute of Technology

Follow this and additional works at: https://digitalcommons.usf.edu/msc_facpub

Part of the Marine Biology Commons

\section{Scholar Commons Citation}

Chambers, Don P. and Willis, Josh K., "Low-Frequency Exchange of Mass Between Ocean Basins" (2009). Marine Science Faculty Publications. 81.

https://digitalcommons.usf.edu/msc_facpub/81

This Article is brought to you for free and open access by the College of Marine Science at Digital Commons @ University of South Florida. It has been accepted for inclusion in Marine Science Faculty Publications by an authorized administrator of Digital Commons @ University of South Florida. For more information, please contact digitalcommons@usf.edu. 


\title{
Low-frequency exchange of mass between ocean basins
}

\author{
Don P. Chambers ${ }^{1,2}$ and Josh K. Willis ${ }^{3}$ \\ Received 14 May 2009; revised 20 July 2009; accepted 31 August 2009; published 5 November 2009.
}

[1] We examine the Gravity Recovery and Climate Experiment (GRACE) data and output from an ocean model to quantify mass fluctuations for the Pacific, Atlantic, and Indian Ocean basins from August 2002 until December 2008. The monthly spatial mean is removed to study interbasin mass exchange. We find a seasonal exchange of mass between the Atlantic and Pacific that is similar to one documented previously, although the amplitude observed by GRACE is about $20 \%$ lower than that simulated by an ocean model. There are also significant fluctuations with periods longer than 1 year. We find large interannual exchanges in 2005 and 2007, with GRACE observing yearly averaged mass anomalies in the Pacific that are about 30-40\% larger than simulated by a model. This is shown to be from significant interannual mass losses from the Indian Ocean that are observed by GRACE but not simulated by the model. A longer run of the model, from 1976 to 2008, suggests that such interbasin mass exchanges are a regular occurrence and can last for as long as a couple of decades.

Citation: Chambers, D. P., and J. K. Willis (2009), Low-frequency exchange of mass between ocean basins, J. Geophys. Res., 114, C11008, doi:10.1029/2009JC005518.

\section{Introduction}

[2] Several investigations have used the multiyear record of the Gravity Recovery and Climate Experiment (GRACE) data to examine changes in sea level associated with exchange of mass between the ocean and the continents and atmosphere [Chambers et al., 2004; Lombard et al., 2007; Willis et al., 2008; Leuliette and Miller, 2009]. Although there are still significant differences in long-term trends depending on which model of glacial isostatic adjustment (GIA) is used, all the studies agree that there are significant global-scale changes in ocean mass on periods between 1 and 4 years. While the time-varying mean ocean mass is a fairly obvious first-order fluctuation in the data, there are also more subtle large-scale ocean mass variations that should have been visible.

[3] Fluctuations resulting from wind-forced redistribution of mass from one ocean basin to another have been simulated by ocean models but have not yet been discussed in light of the new GRACE observations. Such mass exchanges will have no net global signature. However, averages over basins like the Pacific and the Atlantic will show sizable anticorrelated fluctuations. Stammer et al. [1996] first noted that there were seasonal, out-of-phase fluctuations in averaged ocean bottom pressure (OBP) over the Atlantic and Pacific oceans in output from an ocean model. They also noted small, but significant, 2 year trends

\footnotetext{
${ }^{1}$ Center for Space Research, University of Texas at Austin, Austin, Texas, USA.

${ }^{2}$ Now at College of Marine Science, University of South Florida, St. Petersburg, Florida, USA.

${ }^{3}$ Jet Propulsion Laboratory, California Institute of Technology, Pasadena, California, USA.
}

Copyright 2009 by the American Geophysical Union. 0148-0227/09/2009JC005518 in averaged bottom pressure of the entire Atlantic and Pacific basins that were out of phase, although they could not be sure that it was not due to spurious drift in the model. Ponte [1999] performed a more detailed study and demonstrated that the most striking features of the seasonal fluctuation are positive correlations between the Atlantic and Southern oceans and a negative correlation between those basins and the Pacific and northern Indian oceans. Thus, when OBP increases in the Atlantic and Southern Ocean during the northern winter, OBP decreases in the Pacific and Indian oceans by a comparable amount. The pattern reverses 6 months later in northern summer. This indicates significant interbasin mass exchange, which Ponte [1999] linked to small changes in the net transport associated with seasonal changes in the zonal winds in the Southern Ocean. As he noted, a change in net transport of less than $0.1 \mathrm{~Sv}$ is all that is required to raise sea level by $1 \mathrm{~cm}$ in 6 months over an area roughly the size of the Atlantic basin. This is a small fraction of any component of the net transport in the Indonesian Throughflow or across the Drake Passage, for instance.

[4] More recently, Stepanov and Hughes [2006] predicted significant mass exchanges between the Southern Ocean and the Pacific at nonseasonal periods longer than 100 days in a barotropic model. From experiments with changing the topography in the model, they concluded that the mechanism for the transport was the balance of wind stress by form stress in the Drake Passage. In the model used by Stepanov and Hughes [2006] the Southern Ocean bottom pressure signal was highly correlated across all sectors of the Southern Ocean at these time scales; however, it is not clear whether the correlation holds for all periods longer than 100 days, or whether it is dominated by periods between 100 days and the seasonal. As discussed in the first paragraph of section 3, we find evidence that ocean 
bottom pressure signals in the Atlantic, Indian, and Pacific sectors of the Southern Ocean are decorrelated on interannual to decadal time scales. Finally, Wunsch et al. [2007] also found evidence of significant decadal tends in large-scale OBP over some regions in an ocean model that assimilated altimetry and in situ data.

[5] If such long-term changes in basin-averaged OBP (and hence ocean mass) do exist, they have important implications for interpreting sea level change and in studies of depth-averaged ocean transport. For instance, how long can these transports be sustained and what are their sizes? How large of an area do they cover? Are they related to local wind changes or to larger-scale changes in the ocean transport? Decadal-scale internal mass redistributions that cause local sea level changes comparable in magnitude to the global mean sea level signal of $1-3 \mathrm{~mm} \mathrm{yr}^{-1}$ complicate the interpretation of sea level records from tide gauges.

[6] Such large-scale, internal mass redistributions should be visible in the GRACE ocean data, once the monthly spatial mean has been removed. In this paper, we will examine a 6 year time series of ocean mass derived from GRACE data averaged over the Atlantic, Pacific, and Indian oceans and compare the results with output from a baroclinic model that is used as an a priori estimate in the GRACE processing. This model has also recently been run from 1976 to the present, so we can also use its output to quantify longer temporal variations that may exist. We will describe where the GRACE data confirm the model predictions, and, more importantly, where they do not. Before proceeding to a discussion of the results, we will briefly describe some special processing of the GRACE data and the ocean model output, then define and comment on the ocean areas we will be averaging over.

\section{Data Processing}

[7] GRACE does not measure variations in gravity or mass directly but instead measures changes in range between the two GRACE spacecraft. The GRACE project then uses the observed variations in the range rate between the two satellites and other tracking data to estimate the values of gravitational coefficients along with other dynamical orbit parameters in a least squares state estimation problem in order to minimize the misfit between a modeled orbit and the observations [Bettadpur, 2007]. The initial state estimate is based on a number of models, some of which are not updated in the procedure (e.g., solid and ocean tides, atmospheric mass), while others are (e.g., gravity field coefficients). For ocean applications, one of the more important background models is time-variable gravity derived from a version of the University of Hamburg Ocean Model for Circulation and Tides (OMCT) forced by ECMWF winds and pressure at $6 \mathrm{~h}$ intervals [Thomas, 2002; Flechtner, 2007]. OMCT is used to model high-frequency (less than 1 to 2 month period) OBP variations that can cause aliasing in the recovered gravity coefficients. Details of how OBP variations are calculated from the model are given by Flechtner [2007]. In summary, the atmospheric and ocean model pressures are vertically integrated to obtain the pressure at the seafloor. Although OMCT uses the Boussinesq approximation and thus conserves volume and not mass and would cause artificial signals in OBP [e.g., Ponte, 1999], an equivalent, but negative uniform mass layer has been added to remove the effect so that the model will have no global mass variability [e.g., Greatbatch, 1994]. The integrated pressure changes are then converted to global gravity field coefficients for use with the GRACE data [Flechtner, 2007]. Our results are based on converting these gravity coefficients back to OBP using the same equations used for GRACE [e.g., Chambers, 2006a].

[8] One should note, however, that the aliasing reduced by using OMCT is mainly at short wavelengths $(<300 \mathrm{~km}$ half wavelength). Simulations suggest there is no significant long-wavelength, low-frequency aliasing due to errors in modeling the high-frequency OBP [Thompson et al., 2004]. Furthermore, any low-frequency error in the model should be corrected in the state estimation, so when the monthly average of the model is restored to the estimated corrections [e.g., Chambers, 2006a], the full ocean gravity variation is observed correctly. Thus, if the ocean model were exactly correct for all periods, GRACE should not update the a priori estimate over the ocean. However, if the model were completely wrong, the processing should estimate large corrections. To the extent that the processing steps are linear, the sum of the a priori state from the model and estimated corrections should be the same in either case.

[9] This can be demonstrated using two different releases of the GRACE gravity coefficients, which use very different reference ocean models. The initial release of the data (release 01) used a barotropic ocean model that had power mainly at periods less than 90 days [Ali and Zlotnicki, 2003; Flechtner, 2007]. This model is significantly different from OMCT, which is not only baroclinic but also has larger lowfrequency variations. Although the original release 01 data are significantly less accurate than later releases over short wavelengths [Chambers, 2006b], they have similar accuracy over large basins, once several corrections are made to the data to account for larger errors in the degree 2, order 0 coefficient and a missing pole tide correction [Chambers, 2006a]. When averaged over the Pacific Ocean, the ocean models used for release 01 and release 04 have significantly different low-frequency variability (Figure 1a). The variance of the low-frequency OBP in the barotropic model used for release 01 is an order of magnitude smaller than that used from OMCT $\left(0.4 \mathrm{~mm}^{2}\right.$ versus $\left.4 \mathrm{~mm}^{2}\right)$. The phasing of the interannual fluctuations is also significantly different. Despite using very different models in the processing, the low-frequency OBP signals from GRACE are not significantly different (Figure 1b). The correlation between the two estimates is 0.92, and the standard deviation of the difference is $1.2 \mathrm{~mm}$, which is lower than the uncertainty on either time series $(1.5 \mathrm{~mm}$ for release 04 versus $2 \mathrm{~mm}$ for release 01). Similar results hold for other large basins, like the Atlantic and Indian oceans (not shown). Thus, even if no a priori low-frequency OBP variability is modeled, the GRACE observations still recover it. Likewise, any erroneous low-frequency variability in the background model is unlikely to cause erroneous signals in the final GRACE results.

[10] For the remainder of the study, we utilize the Center for Space Research release 04 data [Bettadpur, 2007], restoring the background ocean model using the coefficients supplied by the project [Flechtner, 2007]. As discussed in 
a)

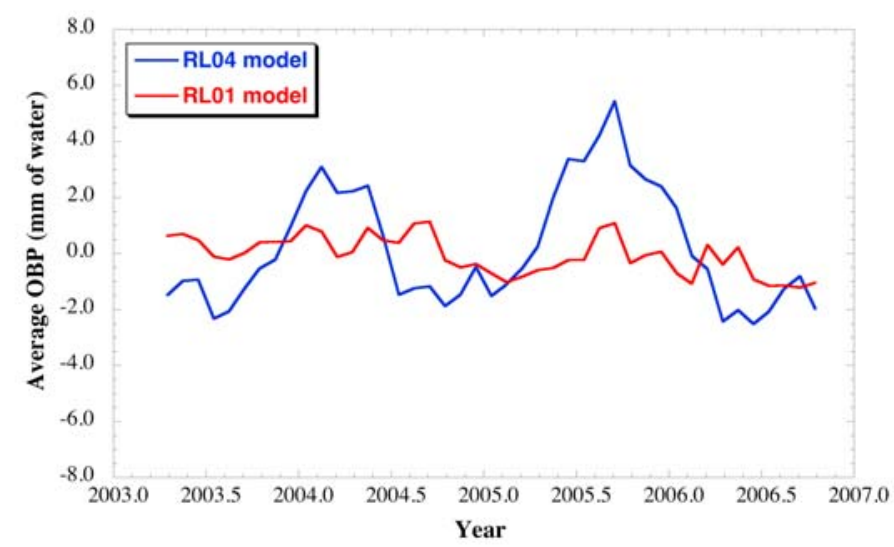

b)

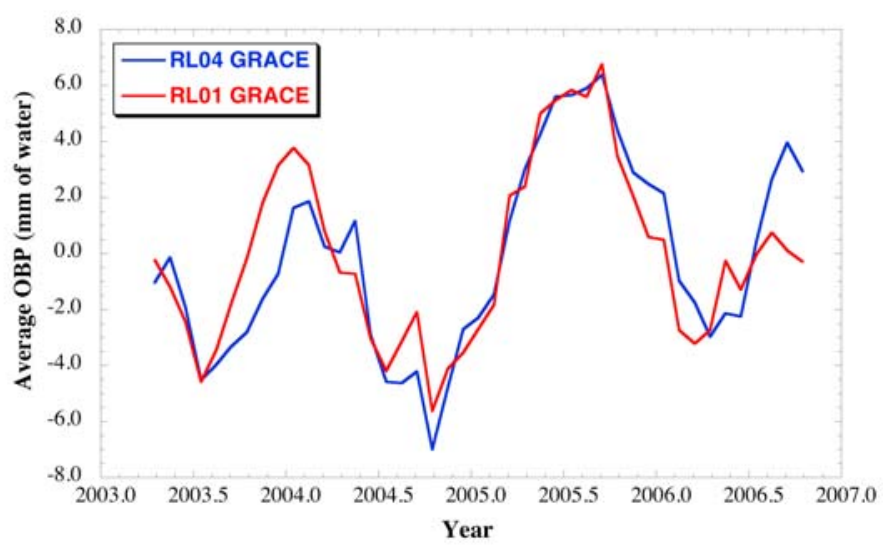

Figure 1. Nonseasonal OBP variations averaged over the Pacific Ocean from (a) the ocean models used for release 01 (RL01) and release 04 (RL04) and (b) GRACE for the same releases. A mean seasonal sinusoid has been removed and a 5 month running mean has been applied to the residuals.

previous papers [e.g., Chambers, 2006a; Willis et al., 2008], one also needs to correct the GRACE coefficients for GIA, geocenter, and errors in the degree 2 , order 0 coefficient. The geocenter model we use is based on a combination of OMCT and mean ocean mass and hydrology variations from GRACE [Swenson et al., 2008]. We have previously demonstrated that including annual geocenter variations is necessary to estimate seasonal OBP from GRACE by comparison with steric-corrected altimetry [Chambers, 2006a]. Our new geocenter model (which includes seasonal and interannual variations) was used with GRACE and tested against an independent ocean model (not used in the geocenter estimate). We found that the new estimate decreased residual RMS significantly throughout the ocean compared to the previous annual-only estimate [Swenson et $a l ., 2008$, Figure 7]. This gives us some confidence that the model is improving OBP estimates. Correction for GIA is necessary because GRACE observes the secular gravitational trend of the solid Earth rebounding from the last glacial maximum, which is not related to ocean bottom pressure variations. The mean effect of the correction to GRACE over the oceans is equivalent to about $1 \mathrm{~mm} \mathrm{yr}^{-1}$ of OBP change globally and has an uncertainty of approximately $25 \%$. The correction differs by $40-50 \%$ of the mean value for the Indian and Atlantic oceans and 10\% for the Pacific. When a monthly global mean OBP is removed from the data to measure internal mass redistribution, a majority of the GIA correction (right or wrong) is removed as well. At most, the Atlantic and Indian oceans may have an error in the secular trend of $25 \%$ of $\pm 0.5 \mathrm{~mm} \mathrm{yr}^{-1}$ (or $\pm 0.12 \mathrm{~mm} \mathrm{yr}^{-1}$ ) due to the correction, but this is small compared to the observed interannual variability.

[11] In order to compute basin-scale mass variations, we utilize the method of averaging kernels multiplied by the GRACE gravity coefficients to determine total mass variations [e.g., Swenson and Wahr, 2002]. Since mass fluctuations are much smaller over the ocean than over the land, one has to be careful when using data near the ocean-land boundary to avoid leakage of land variations into the ocean. In a recent simulation [Chambers, 2009], we demonstrated that using kernels that mask the ocean within $300 \mathrm{~km}$ of continental shorelines minimizes the leakage from continental hydrology as well as Greenland and Antarctica ice sheet melting. We have utilized ocean kernels for the Atlantic, Pacific, and Indian oceans, as shown in Figure 2. We note that the global ocean kernel includes all the basins shown in Figure 2 as well as the Arctic Ocean (not shown). We have chosen not to include Arctic data in this analysis, since leakage from surrounding hydrology can be very large and must be carefully accounted for [Morison et al., 2007]. We did no additional smoothing on the GRACE coefficients, as we found in a simulation that any additional smoothing on release 04 quality data increased the leaked error from hydrology more than it reduced the GRACE errors when averaged over large ocean areas [Chambers, 2009]. The OBP variation measured by GRACE (and OMCT) contains signals from sources other than the internal mass redistribution, however. These signals arise from global temporal variations in ocean mass related to the water cycle (for GRACE) and to variations in the global mean atmospheric pressure over the ocean (GRACE and $\mathrm{OMCT}$ ). It is straightforward to estimate and remove

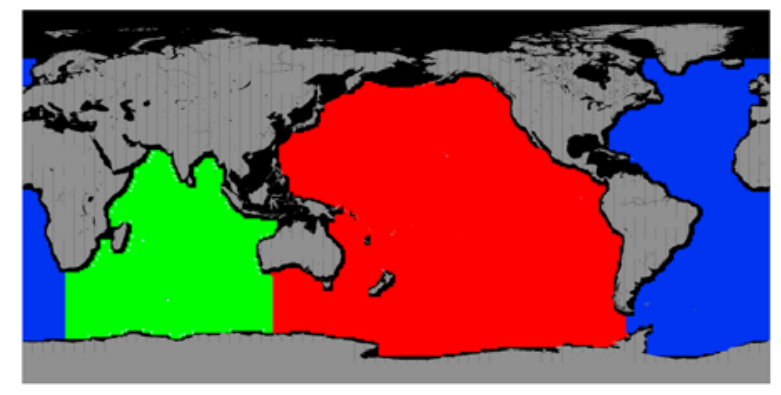

Figure 2. Basin area definitions used in this analysis: Pacific Ocean (red), Atlantic Ocean (blue), Indian Ocean including Arabian Sea and Bay of Bengal (Green). 


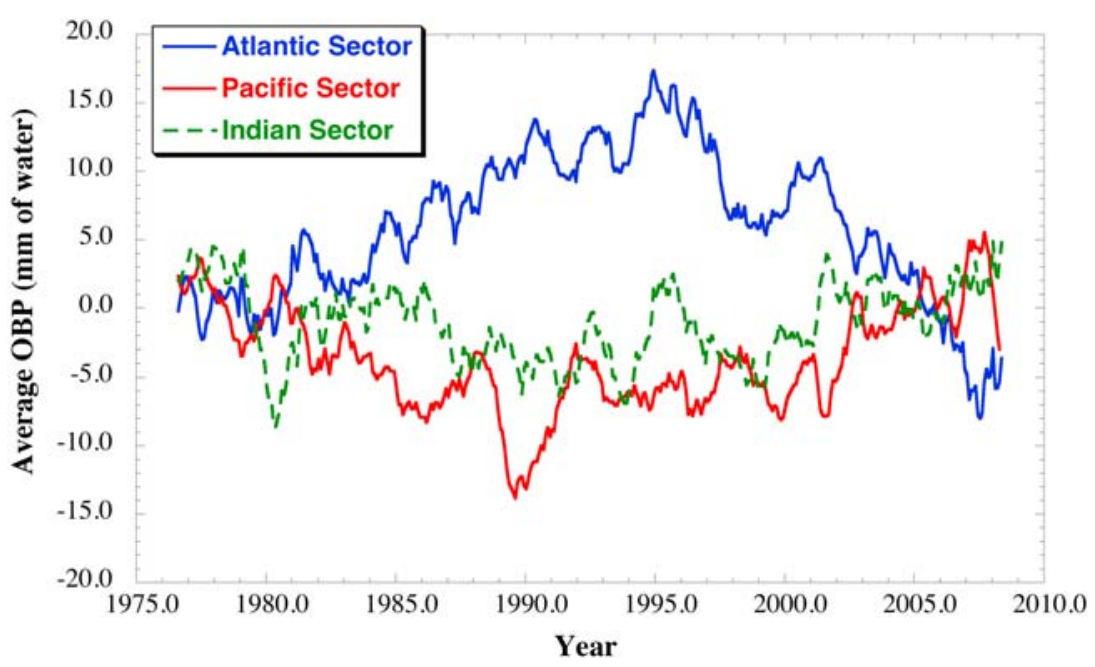

Figure 3. Low-pass filtered ( $>13$ months) average OBP for the Atlantic sector (blue), Pacific sector (red), and Indian sector (green dashed) of the Southern Ocean (defined as all regions south of $35^{\circ} \mathrm{S}$ ) computed from OMCT. The data were low-pass filtered by first estimating and removing seasonal sinusoids then smoothing the residuals with a 13 month running mean.

the monthly global mean of the GRACE and OMCT data from the basin-averaged time series in order to isolate the internal mass redistribution signal.

\section{Results and Discussion}

[12] Before discussing the results of our analysis, we will discuss the rationale for the choice of basins averages. Stepanov and Hughes [2006] treated all the ocean area south of $35^{\circ} \mathrm{S}$ as one Southern Ocean basin and examined the exchange of mass between the entire Southern Ocean and the Atlantic, Pacific, and Indian Ocean basins north of $35^{\circ} \mathrm{S}$. Other studies have shown all regions of the Southern Ocean to be significantly correlated at seasonal periods [e.g., Ponte, 1999], but it is not clear from these analyses or the one of Stepanov and Hughes [2006] whether the same holds for longer periods. To test this, we computed average ocean bottom pressure for the 3 sectors of the Southern Ocean from the recently released longer run of the OMCT dealiasing model (F. Flechtner, personal communication, 2008). We used monthly averages from January 1976 to December 2008 with 33 year trends removed. Removal of the trends was necessary because of very large (several $\mathrm{cm} \mathrm{yr}^{-1}$ ) linear drifts in some regions, which we assume were due to model drift. We low-pass filtered the time series by first estimating and removing the strongly correlated seasonal variations, then smoothing with a 13 month running mean. The results suggest that the average low-frequency OBP in

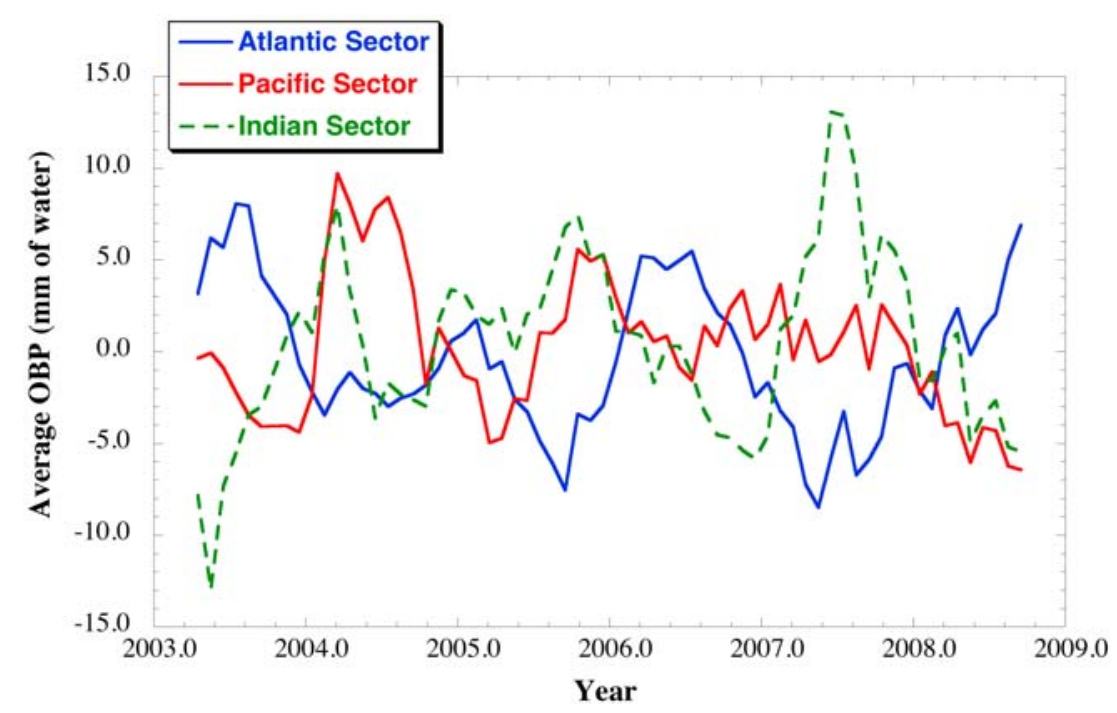

Figure 4. Low-pass filtered ( $>5$ months) average OBP for the Atlantic sector (blue), Pacific sector (red), and Indian sector (green dashed) of the Southern Ocean computed from GRACE. The data were low-pass filtered by first estimating and removing seasonal sinusoids then smoothing the residuals with a 5 month running mean. 


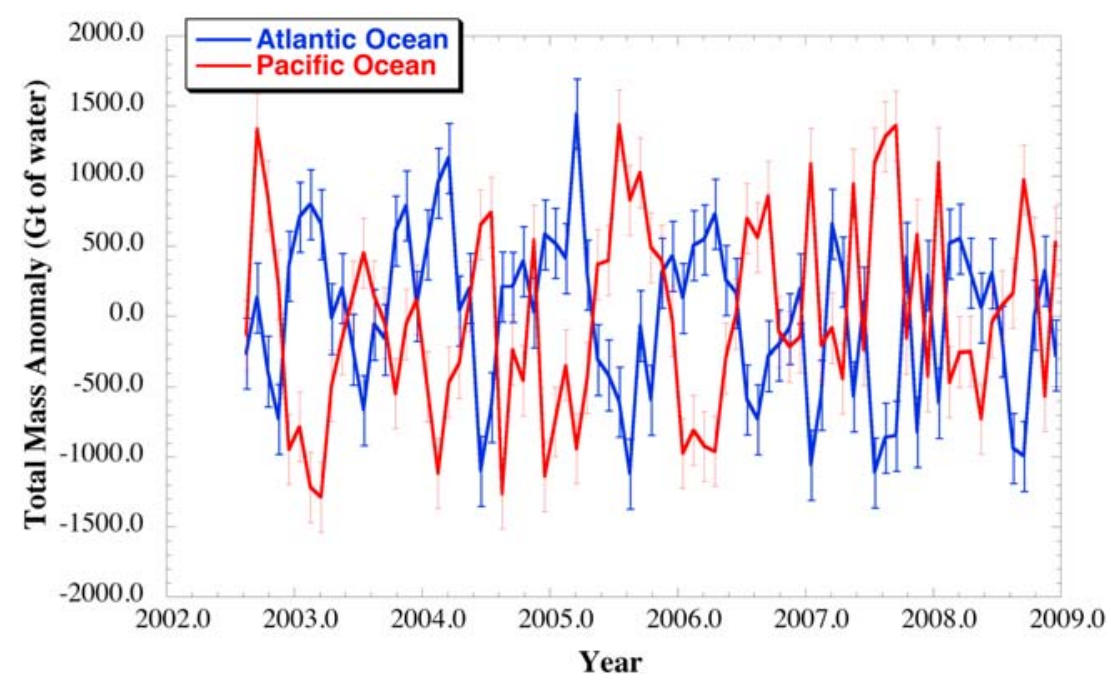

Figure 5. Monthly total mass anomaly for the Atlantic Ocean (blue) and Pacific Ocean (red) observed by GRACE. Error bars are the $95 \%$ confidence level, based on monthly errors for gravity coefficients reported by the project, leakage errors based on a simulation [Chambers, 2009], and uncertainty of the mean mass signal that was removed.

the three Southern Ocean sectors are not significantly positively correlated (Figure 3). The correlation between the Indian and Pacific sectors is significantly different than 0 but is still low at 0.33 . The correlation between the Indian and Atlantic sectors is negative $(-0.37)$, while the correlation between the Pacific and Atlantic sectors is very high and negative $(-0.78)$. The correlation between the Atlantic sector of the Southern Ocean and the Atlantic north of the Southern Ocean, however, is 0.78. Thus, in OMCT, the various sectors of the Southern Ocean are not highly correlated for periods longer than 1 year, but the large-scale variations within the basin are.

[13] Although these results are from a model and the correlations may be inflated because of nonlinear drifts, the short record of observations from GRACE suggests similar anticorrelated behavior between the three sectors at longperiods (Figure 4). There are not enough independent observations to compute correlations with high confidence, but only the Atlantic and Indian Ocean sectors have a correlation that is significantly different than 0 , and it is negative $(-0.63)$. Because of this, we will not treat the Southern Ocean as a separate basin but will include it in the three larger basins defined in Figure 2. Any mass exchange between the Southern Ocean and the Pacific north of the Southern Ocean [e.g., Stepanov and Hughes, 2006] will not be discernable. However, we will be able to quantify the exchange of mass between the three larger basins, which has not been examined previously.

[14] When one examines the basin-averaged time series after removing the monthly global mean values, it is clear there are large anticorrelated fluctuations in the total mass of the Atlantic and Pacific Oceans at a multitude of periods (Figure 5). We use total basin mass instead of average OBP (or equivalent mean sea level change), as it is area independent and therefore allows direct comparisons between basins. The largest fluctuations are of order 1000 Gigatons (Gt) $\left(1000 \times 10^{12} \mathrm{~kg}\right)$, which is equivalent to an average sea level change over the Atlantic of $1.4 \mathrm{~cm}$. Some of the pulses can change sign in 1 or 2 months (e.g., in late 2007), while others are more seasonal. The general timing of the exchange is similar to what was previously observed in a model by Ponte [1999]: mass is typically higher than normal in the winter in the Atlantic and lower in the Pacific. However, there are clearly large deviations in this seasonal cycle, with significant changes in amplitude and phase from year to year. Note the nearly complete lack of the seasonal cycle in late 2006, early 2007.

[15] The observed mean annual amplitudes of the Atlantic and Pacific mass variations agree within the uncertainty (Table 1), and they are almost exactly $180^{\circ}$ out of phase, with the mass gain in the Atlantic occurring in midFebruary as simulated by OMCT. The semiannual variation shows a similar out-of phase pattern. GRACE does not observe a large annual mass fluctuation in the Indian Ocean, which is consistent with Ponte [1999], who found mainly seasonal exchanges within the Indian Ocean. The OMCT model, on the other hand, predicts much higher mass transports into and out of the Indian Ocean on annual periods (Table 2). This is reflected in annual amplitudes that are 5 times larger in the model for the Indian Ocean and approximately $20-25 \%$ higher in the other two basins compared to those observed by GRACE.

Table 1. Estimated Seasonal Amplitude and Phase for Variations in Total Basin Mass Estimated From GRACE After Removing Global Ocean Mass Variation $^{\mathrm{a}}$

\begin{tabular}{lcccc}
\hline Basin & $\begin{array}{c}\text { Annual } \\
\text { Amplitude (Gt) }\end{array}$ & $\begin{array}{c}\text { Annual } \\
\text { Phase (deg) }\end{array}$ & $\begin{array}{c}\text { Semiannual } \\
\text { Amplitude }(\mathrm{Gt})\end{array}$ & $\begin{array}{c}\text { Semiannual } \\
\text { Phase (deg) }\end{array}$ \\
\hline Atlantic & $465 \pm 80$ & $44 \pm 10$ & $221 \pm 80$ & $201 \pm 21$ \\
Pacific & $535 \pm 80$ & $232 \pm 8$ & $136 \pm 80$ & $9 \pm 34$ \\
Indian & $22 \pm 80$ & $213 \pm 214$ & $78 \pm 80$ & $68 \pm 60$ \\
\hline
\end{tabular}

${ }^{\mathrm{a}}$ Annual and semiannual period sinusoids were fit to each time series from August 2002 until December 2008 along with a bias and trend using least squares. Phase $(\varphi)$ is in degrees relative to 1 January according to Acos $(w t-\varphi)$. Uncertainty is the $95 \%$ confidence level, based on monthly errors for gravity coefficients reported by the project, leakage errors based on a simulation [Chambers, 2009], and uncertainty of the mean mass signal that was removed. 
Table 2. Estimated Seasonal Amplitude and Phase for Variations in Total Basin Mass Estimated From the Ocean Model Used in Background Processing After Removing Monthly Spatial Mean ${ }^{a}$

\begin{tabular}{lcccc}
\hline Basin & $\begin{array}{c}\text { Annual } \\
\text { Amplitude (Gt) }\end{array}$ & $\begin{array}{c}\text { Annual } \\
\text { Phase (deg) }\end{array}$ & $\begin{array}{c}\text { Semiannual } \\
\text { Amplitude (Gt) }\end{array}$ & $\begin{array}{c}\text { Semiannual } \\
\text { Phase (deg) }\end{array}$ \\
\hline Atlantic & $579 \pm 60$ & $34 \pm 6$ & $117 \pm 61$ & $230 \pm 30$ \\
Pacific & $635 \pm 85$ & $215 \pm 8$ & $50 \pm 85$ & $327 \pm 97$ \\
Indian & $108 \pm 37$ & $218 \pm 19$ & $19 \pm 36$ & $132 \pm 112$ \\
\hline
\end{tabular}

${ }^{\mathrm{a}}$ Uncertainties are formal errors only.

[16] The mean seasonal interbasin exchange of mass, while significant, explains only $35-40 \%$ of the total variance of the basin-scale mass fluctuations. When the residuals relative to a seasonal fit are plotted after low-pass filtering with a 5 month running mean (Figure 6), we find significant interannual exchange of mass between the Atlantic and Indian oceans with the Pacific. The magnitude of the largest interannual variation is of the same order as the seasonal amplitude. If the correlation between each basin average time series and maps of OBP variability from GRACE are computed (Figure 7), one finds that large areas of each basin have interannual variability that is in phase with the basin average. This suggests that the fluctuation truly is large-scale and not reflective of very large variability in one isolated area. It is also interesting to note the significant correlation between the Indian Ocean and Atlantic Ocean, and the significant negative correlation between the Pacific and Atlantic/Indian oceans. Not all regions have significant correlation with the basin average, however, especially in the Pacific. It has been demonstrated that there is large mass redistribution within the Pacific [e.g., Stepanov and Hughes, 2006] that can mask a weaker, long-wavelength fluctuation.

[17] Although GRACE and OMCT observe average exchanges of mass in each basin at nearly the same time (Figure 8), the observed variations are generally higher than those modeled. For instance, the interannual mass gains in the Pacific in 2005 and 2007 observed by GRACE are about $30 \%$ higher than simulated by the model. In 2005 , this is caused by nearly equal amounts of mass loss from the
Atlantic and Indian Ocean at the same time. Although the model simulated the Atlantic variation fairly accurately, it underestimated the Indian Ocean change by nearly $50 \%$. In early 2007, there was a large decrease in ocean mass in the Atlantic that was not simulated by the model. At the same time, GRACE observed a multiyear loss of mass from the Indian Ocean that is not reflected in the model. The smaller interannual variation in 2004 is also different: GRACE observes a later loss in Atlantic Ocean mass than simulated by the model, which causes a slight phase shift in the Pacific gain. Although it appears that there might be a longer-term trend in the mass exchange after early 2005 , especially in the Indian Ocean, the interannual fluctuations are far too large to quantify if such a trend exists with any certainty. Overall, OMCT explains about $70-80 \%$ of the variance observed by GRACE in the Atlantic and Pacific but only $33 \%$ in the Indian Ocean.

[18] One can estimate the change in net transport needed to sustain these interannual fluctuations and compare them to the seasonal transport changes [e.g., Ponte, 1999]. The transport needed for the mean seasonal exchange between the Atlantic and the Pacific is approximately $32,000 \mathrm{~m}^{3} \mathrm{~s}^{-1}$, or $0.03 \mathrm{~Sv}$. A fluctuation of only half of this for 1 year could cause the observed interannual fluctuations in 2005 and 2007. Small imbalances in flow through the Bering Straits, the Indonesian Throughflow, the Drake Passage, or in the Antarctic Circumpolar Current could easily account for such small changes in mass exchange between the basins. These subtle and very small imbalances are impossible to measure and difficult to model, although OMCT appears to be getting the signal correct at the $70 \%$ level for the Pacific and Atlantic but only $30 \%$ for the Indian Ocean. It was originally proposed that such small transports could be determined if GRACE could measure OBP accurately enough. This study confirms this is possible, although it is still impossible to pinpoint the source of the change with GRACE data alone.

[19] We cannot examine variations in interbasin mass exchange at periods longer than 3 to 4 years with the current time series from GRACE. However, we have used the GRACE data to verify that the OMCT model predicts a)

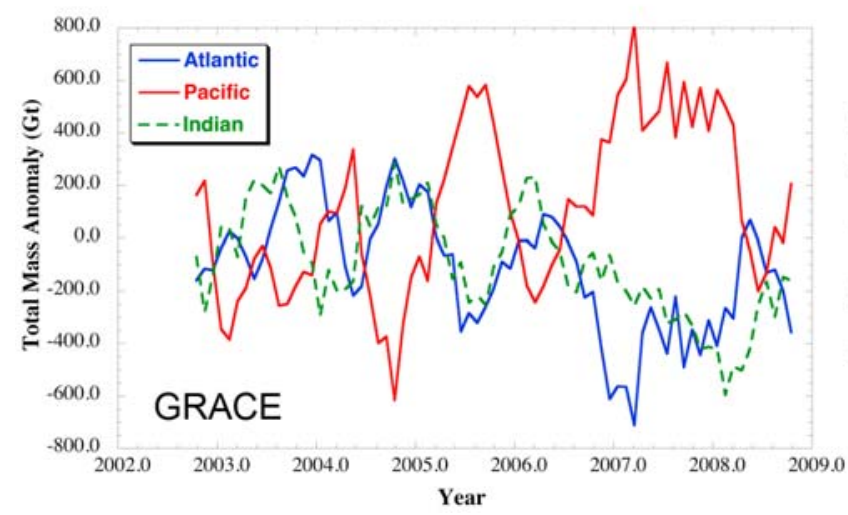

b)

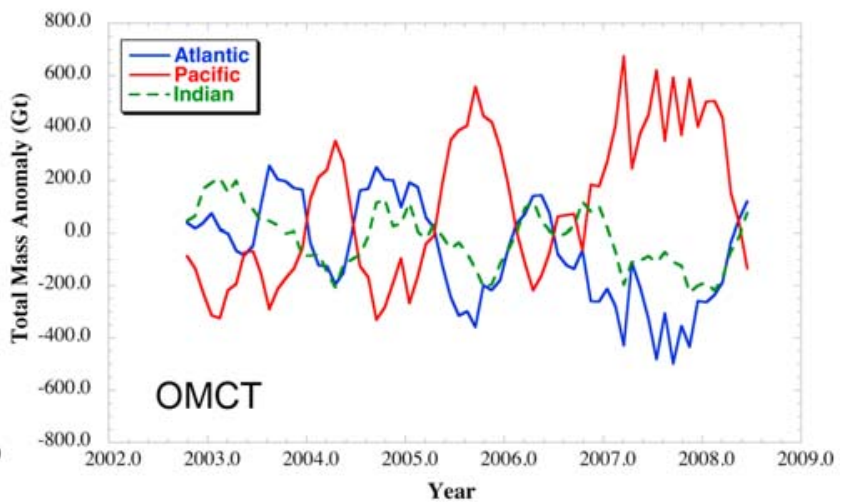

Figure 6. Nonseasonal total mass anomaly for the Atlantic Ocean (blue) and Pacific Ocean (red), and Indian Ocean (green dashed) observed by (a) GRACE and (b) OMCT. A mean seasonal sinusoid has been removed and a 5 month running mean has been applied to the residuals. Data have been referenced to the mean from January 2003 to December 2005. 
a)

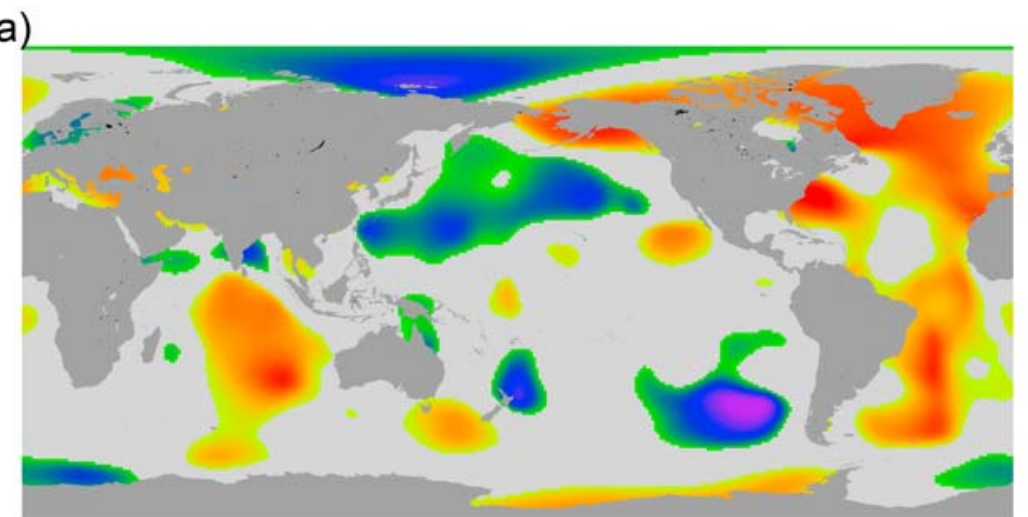

b)

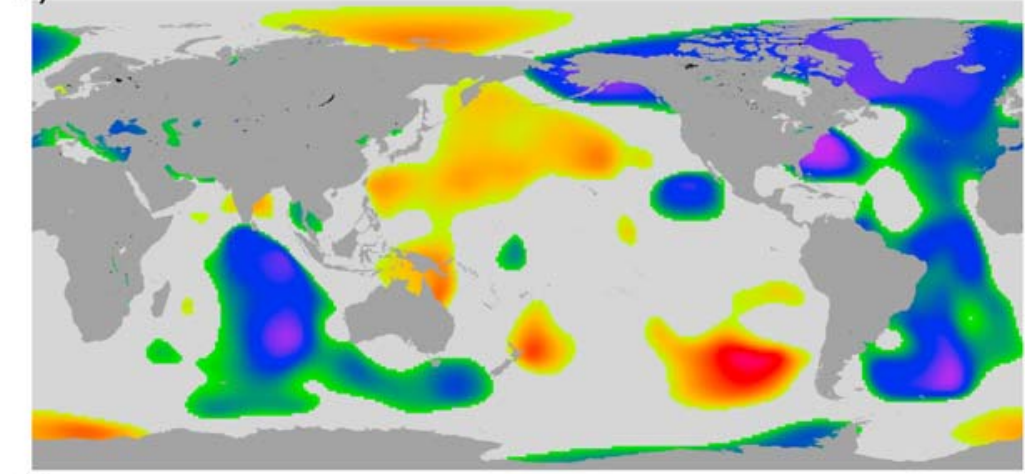

c)
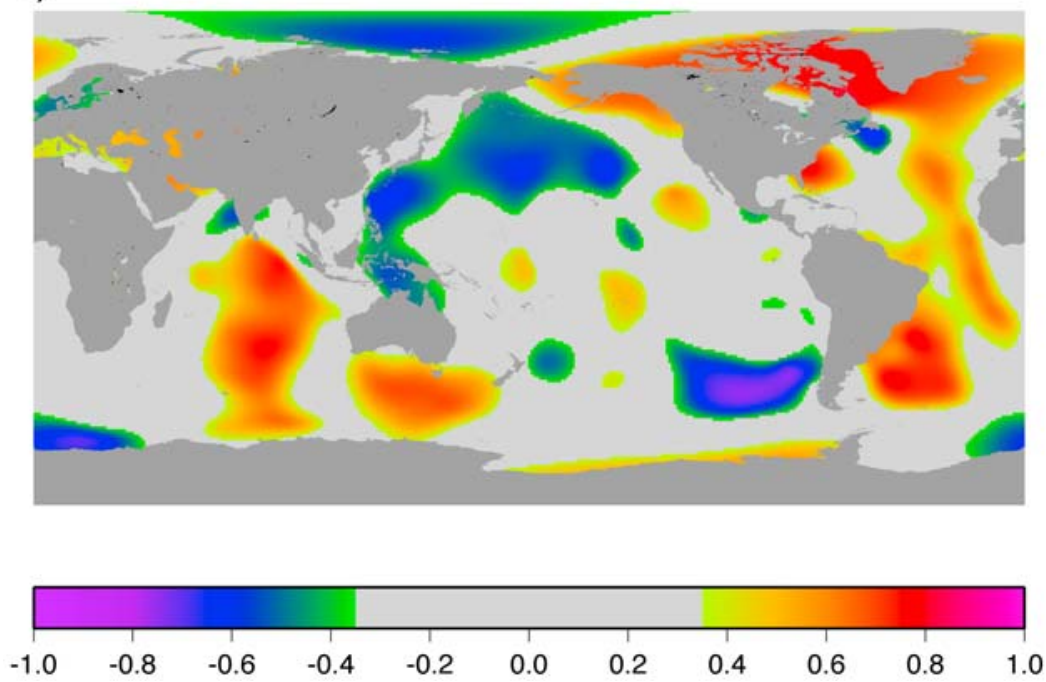

Figure 7. Correlation between gridded OBP from GRACE and the basin-averaged time series in Figure 6 for the (a) Atlantic Ocean, (b) Pacific Ocean, and (c) the Indian Ocean. In each map, the same gridded data (750 km smoothed data from http://grace.jpl.nasa.gov with global means removed) are used, but only the time series used in the correlation is changed.

the general periodicity of mass exchange between the Atlantic and Pacific oceans, albeit with some attenuation of the peaks. In addition, some small but significant interannual differences occur between model and observations in the Indian Ocean. Nevertheless, the agreement suggests that we can use the longer run of OMCT from 1976 to investigate possible mass exchanges on longer time scales. After removing the mean seasonal variation and smoothing with a 13 month running mean (Figure 9), the model predicts exchanges of up to $600 \mathrm{Gt}$ in 3 years during several periods (1979-1981, 1995-1998, 2003-2007). Perhaps more striking, however, is the large exchange of mass from the Pacific to the Atlantic between 1977 and 1995 that reversed between 1995 and 2008. The average transport required to sustain this exchange would be $0.001 \mathrm{~Sv}$.

[20] Although the GRACE observations have verified the existence of at least 3 year fluctuations, it will be difficult to 


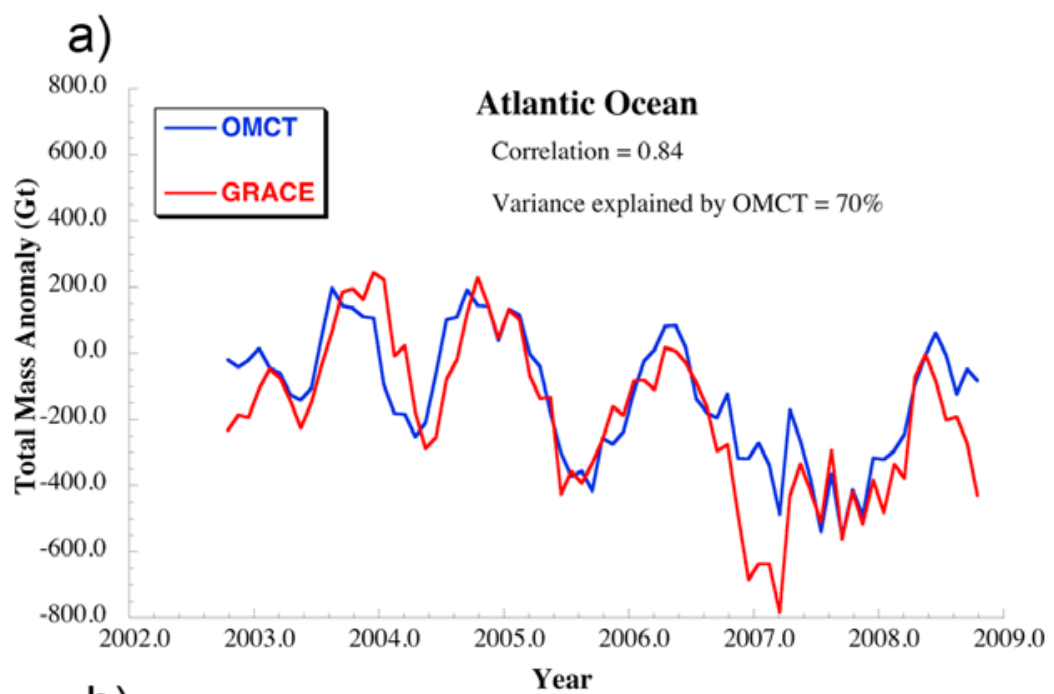

b)

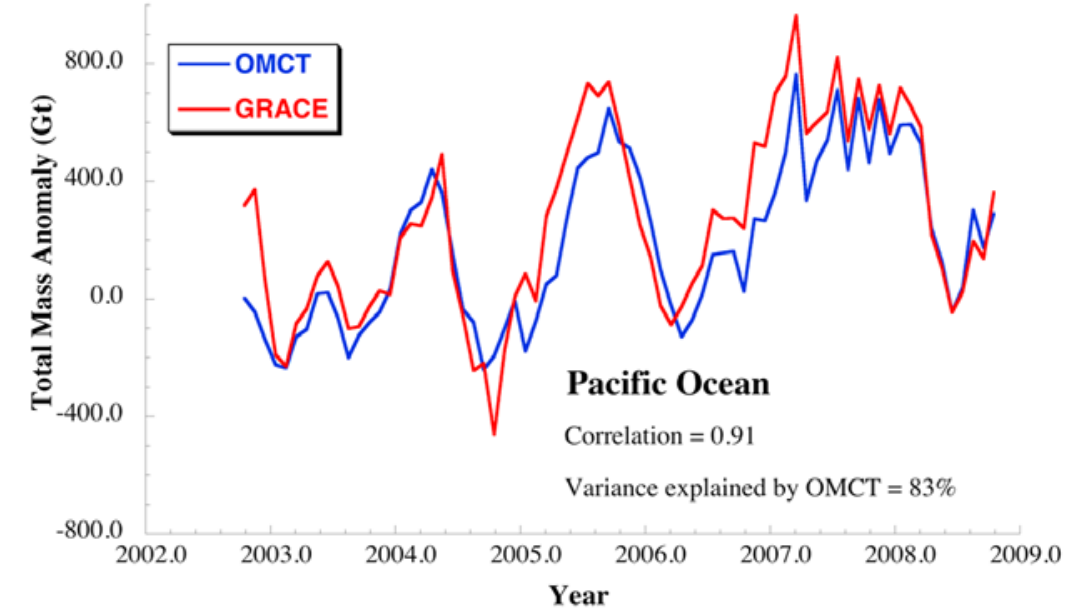

c)

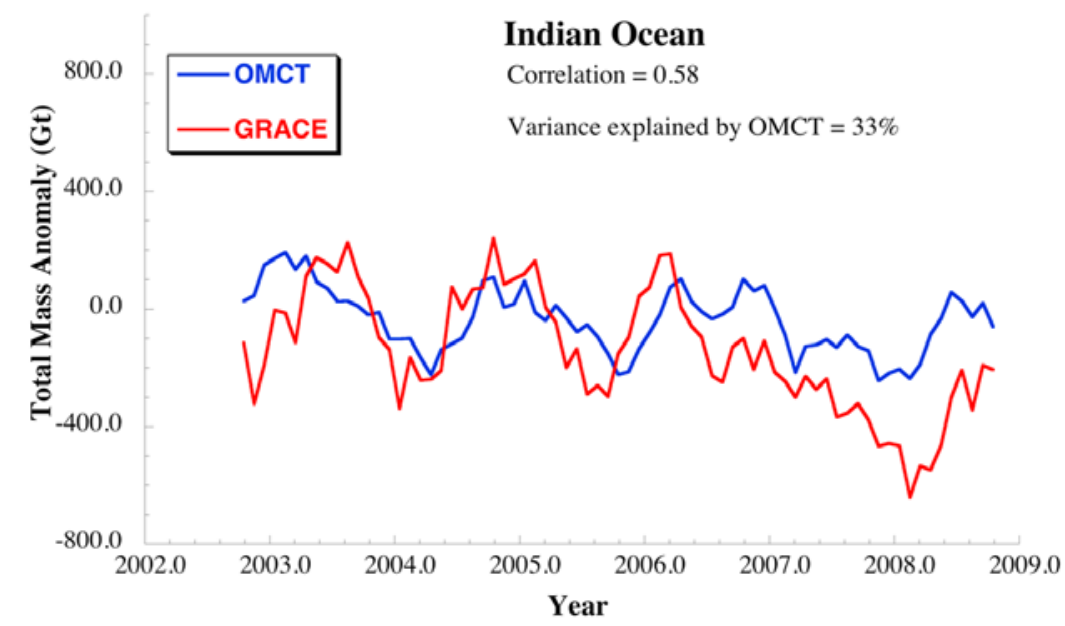

Figure 8. Same as Figure 6, except comparing GRACE (red) and OMCT (blue) time series for each basin: (a) Atlantic, (b) Pacific, and (c) Indian Ocean.

verify whether the model predictions for longer periods are real in the short term. It may be possible to examine such an exchange with long tide gauge records, as the predicted 2 decade change would cause an approximately $9 \mathrm{~mm}$ rise in the Atlantic and $4 \mathrm{~mm}$ drop in the Pacific, leading to a sea level difference between the basins of $13 \mathrm{~mm}$. This may be difficult to detect in individual tide gauge records, as they may contain other decadal signals of similar magnitude 


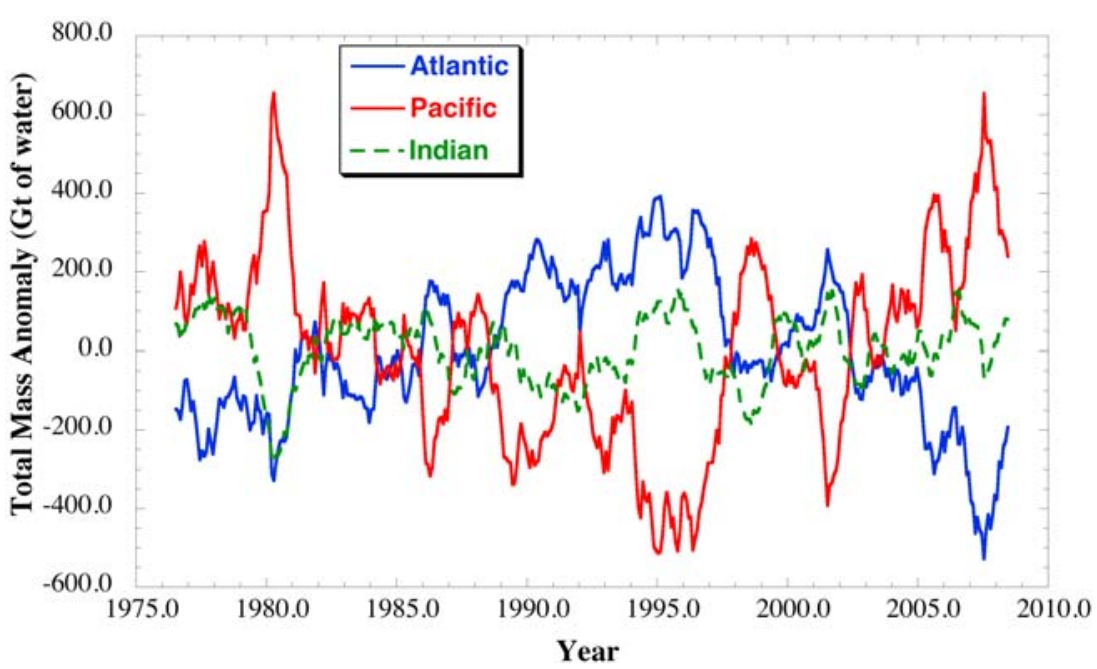

Figure 9. The 13 month running mean of total mass anomaly for the Atlantic Ocean (blue) Pacific Ocean (red), and Indian Ocean (green dashed) predicted by OMCT. A 33 year linear trend and a seasonal sinusoid have also been removed.

[Miller and Douglas, 2007]. However, by examining yearly averages of satellite altimetry and tide gauge data corrected for steric fluctuations [e.g., Willis et al., 2004], it may be possible to isolate the basin-scale mass exchange, provided there are no long-term systematic errors (e.g., drifts, sampling error) in any of the data sets.

\section{Conclusions}

[21] Previous studies have pointed out exchanges of mass between the Atlantic and Pacific oceans at seasonal periods [e.g., Stammer et al., 1996; Ponte, 1999] and the Southern Ocean and Pacific for periods of 100 days or more [Stepanov and Hughes, 2006]. However, a closer examination of model output and GRACE data indicates interannual exchanges also exist and are not confined to an exchange between the Southern Ocean and Pacific. From 2003 to 2008 , there were at least three fluctuations over a year or longer with peak exchanges that were the same size as the mean seasonal variation. Although an ocean model simulated the periodicity of the mass exchanges well, the simulated amplitudes of the seasonal exchange were about $25 \%$ smaller than observed by GRACE. GRACE also observes much larger interannual mass variations in the Indian Ocean that are correlated with the Atlantic Ocean, unlike the model, which predicts very small interannual variations in the Indian Ocean. This leads to a $40 \%$ larger mass gain in the Pacific than simulated.

[22] This is the first direct observation of such a lowfrequency exchange of ocean mass from one basin to another. This may be the source of the 2 year trend Stammer et al. [1996] noted in their analysis of a short model run. The fact that such variations exist has important implications in studies of deep ocean transport and sea level. For instance, what is the source of the approximate 2 year fluctuations in mass exchange we have observed between 2005 and 2007? Is it caused by a change in transport in one area (e.g., the Antarctic Circumpolar Current) or a change at multiple locations like the Bering Straits and the Indonesian
Throughflow? This will be a difficult question to answer in the near term.

[23] There is evidence of a steady loss of mass from the Indian Ocean from 2006 through 2009. A linear trend fit over this interval explains nearly $70 \%$ of the variance. It will be interesting to see if this continues, or whether it reverses in the next year. A long run of OMCT suggests that mass exchanges can last for up to 2 decades. Although the same signal will be present in sea level records, it will be small compared to steric signals and may be difficult to detect. We hope that GRACE continues for several more years and is followed by a similar type of mission without a long gap, so the existence of such long period fluctuations can be tested using observations.

[24] Acknowledgments. We would like to thank four anonymous reviewers for their comments on two earlier drafts of this paper, which led to significant changes in the structure. We would also like to thank C. Hughes for pointing us to his paper after seeing a presentation of these results. We would also like to thank F. Flechtner and M. Thomas for providing the very long run of the OMCT OBP output; they are available from the Information System and Data Center (ISDC) at GeoForschungsZentrum (GFZ) Potsdam. The GRACE data and OMCT output are furnished by the GRACE Science Data System and are available at the NASA Physical Oceanography Distributed Active Archive Center (PO.DAAC) at Jet Propulsion Laboratory, Pasadena, California. This research was carried out under a grant from the NASA GRACE Science Team.

\section{References}

Ali, A. H., and V. Zlotnicki (2003), Quality of wind stress fields measured by the skill of a barotropic ocean model: Importance of stability of the Marine Atmospheric Boundary Layer, Geophys. Res. Lett., 30(3), 1129, doi:10.1029/2002GL016058.

Bettadpur, S. (2007), Level-2 gravity field product user handbook, CSR Publ. GR-03-01, rev 2.3, 19 pp., Univ. of Tex. at Austin, Austin, Tex. Chambers, D. P. (2006a), Observing seasonal steric sea level variations with GRACE and satellite altimetry, J. Geophys. Res., 111, C03010, doi:10.1029/2005JC002914.

Chambers, D. P. (2006b), Evaluation of new GRACE time-variable gravity data over the ocean, Geophys. Res. Lett., 33, L17603, doi:10.1029/ 2006GL027296.

Chambers, D. P. (2009), Calculating trends from GRACE in the presence of large changes in continental ice storage and ocean mass, Geophys. J. Int., 176, 415-419, doi:10.1111/j.1365-246X.2008.04012.x. 
Chambers, D. P., J. Wahr, and R. S. Nerem (2004), Preliminary observations of global ocean mass variations with GRACE, Geophys. Res. Lett., 31, L13310, doi:10.1029/2004GL020461.

Flechtner, F. (2007), AOD1B product description document for product releases 01 to 04, CSR Publ. GR-GFZ-AOD-0001, rev. 3.1, 43 pp., Univ. of Tex. at Austin, Austin, Tex.

Greatbatch, R. (1994), A note on the representation of steric sea level in models that conserve volume rather than mass, J. Geophys. Res., 99, 12,767-12,771, doi:10.1029/94JC00847.

Leuliette, E. W., and L. Miller (2009), Closing the sea level rise budget with altimetry, Argo, and GRACE, Geophys. Res. Lett., 36, L04608, doi:10.1029/2008GL036010.

Lombard, A., D. Garcia, G. Ramillien, A. Cazenave, R. Biancale, J. M. Lemoine, F. Flechtner, R. Schmidt, and M. Ishii (2007), Estimation of steric sea level variations from combined GRACE and Jason-1 data, Earth Planet. Sci. Lett., 254, 194-202, doi:10.1016/j.eps1.2006.11.035.

Miller, L., and B. C. Douglas (2007), Gyre-scale atmospheric pressure variations and their relation to 19th and 20th century sea level rise, Geophys. Res. Lett., 34, L16602, doi:10.1029/2007GL030862.

Morison, J., J. Wahr, R. Kwok, and C. Peralta-Ferriz (2007), Recent trends in Arctic Ocean mass redistribution revealed by GRACE, Geophys. Res. Lett., 34, L07602, doi:10.1029/2006GL029016.

Ponte, R. (1999), A preliminary model study of the large-scale seasonal cycle in bottom pressure over the global ocean, J. Geophys. Res., 104, 1289-1300, doi:10.1029/1998JC900028.

Stammer, D., R. Tokmakian, A. Semtner, and C. Wunsch (1996), How well does a $1 / 4^{\circ}$ global circulation model simulate large-scale oceanic observations?, J. Geophys. Res., 101, 25,779-25,811, doi:10.1029/96JC01754.

Stepanov, V. N., and C. W. Hughes (2006), Propagation of signals in basinscale ocean bottom pressure from a barotropic model, J. Geophys. Res., 111, C12002, doi:10.1029/2005JC003450.
Swenson, S., and J. Wahr (2002), Methods for inferring regional surfacemass anomalies from Gravity recovery and Climate Experiment (GRACE) measurements of time-variable gravity, J. Geophys. Res., 107(B9), 2193, doi:10.1029/2001JB000576.

Swenson, S. C., D. P. Chambers, and J. Wahr (2008), Estimating geocenter variations from a combination of GRACE and ocean model output, J. Geophys. Res., 113, B08410, doi:10.1029/2007JB005338.

Thomas, M. (2002), Ocean induced variations of Earth's rotation-Results from a simultaneous model of global ocean circulation and tides, $\mathrm{Ph}$. $\mathrm{D}$. dissertation, 129 pp., Univ. of Hamburg, Hamburg, Ger.

Thompson, P. F., S. V. Bettadpur, and B. D. Tapley (2004), Impact of short period, non-tidal, temporal mass variability on GRACE gravity estimates, Geophys. Res. Lett., 31, L06619, doi:10.1029/2003GL019285.

Willis, J. K., D. Roemmich, and B. Cornuelle (2004), Interannual variability in upper ocean heat content, temperature, and thermosteric expansion on global scales, J. Geophys. Res., 109, C12036, doi:10.1029/2003JC002260.

Willis, J. K., D. P. Chambers, and R. S. Nerem (2008), Assessing the globally averaged sea level budget on seasonal to interannual time scales, J. Geophys. Res., 113, C06015, doi:10.1029/2007JC004517.

Wunsch, C., R. M. Ponte, and P. Heimbach (2007), Decadal trends in sea level patterns: 1993-2004, J. Clim., 20, 5889-5911, doi:10.1175/ 2007JCLI1840.1.

D. P. Chambers, College of Marine Science, University of South Florida, St. Petersburg, FL 33701, USA. (chambers@csr.utexas.edu)

J. K. Willis, Jet Propulsion Laboratory, California Institute of Technology, M/S 300-323, 4800 Oak Grove Dr., Pasadena, CA 91109, USA. 